\title{
On the Nature of C-H $\cdots \mathrm{F}-\mathrm{C}$ Interactions in Hindered $\mathrm{CF}_{3}-\mathrm{C}\left(\mathrm{sp}^{3}\right)$ Bond Rotations
}

\author{
Prof. Dr. G. K. Surya Prakash", Fang Wang, Dr. Martin Rahm, Dr. Jingguo Shen, Dr. \\ Chuanfa Ni, Prof. Dr. Ralph Haiges, and Prof. Dr. George A. Olah* \\ Loker Hydrocarbon Research Institute and Department of Chemistry University of Southern \\ California University Park, Los Angeles, CA-90089-1661 (USA)
}

\section{Keywords}

conformational isomerism; hydrogen bondings; steric hindrance; cinchona alkaloids; fluorine

Hindered rotations about single bonds ${ }^{1}$ are of immense scientific significance due to their applications in the investigation of intramolecular interactions, ${ }^{2}$ in asymmetric synthesis and catalysis, ${ }^{3}$ as well as in many other fields. ${ }^{4}$ Although slow rotations of many bulky tetrahedral moieties are frequently reported ${ }^{5}$ restricted $\mathrm{F}_{3} \mathrm{C}-\mathrm{C}\left(s p^{3}\right)$ single bond rotations have only been sporadically documented. ${ }^{6,7,8}$ As they are generated via strong non-covalent interactions between the $\mathrm{CF}_{3}$ group and its surrounding atoms $(\mathrm{X})$, hindered $\mathrm{CF}_{3}$ rotations offer ideal opportunity for investigating various $\mathrm{C}-\mathrm{F} \cdots \mathrm{X}$ interactions. In particular, $\mathrm{C}-\mathrm{F} \cdots \mathrm{H}-$ $\mathrm{N} / \mathrm{O}$ hydrogen bondings have received much attention in the fields of physical organic and biological chemistry, whereas prevalence and energetic importance of C-F $\cdots \mathrm{H}-\mathrm{C}$ interactions are frequently debated. ${ }^{9}$ To address these problems, we have investigated $\mathrm{CF}_{3^{-}}$ $\mathrm{C}\left(s p^{3}\right)$ rotations in $O$-alkyl-9-dehydro-9-trifluoromethyl-9-epiquinidine scaffolds. Extremely short C-F $\cdots \mathrm{H}-\mathrm{C}$ distances have been observed both in solution and in the solid state, providing insights into the nature of $\mathrm{C}-\mathrm{H} \cdots \mathrm{F}-\mathrm{C}$ interactions.

9-Dehydro-9-trifluoromethyl-9-epiquinidine (1) was recently synthesized in our laboratory to enable the conformational study of cinchona alkaloids in various solvents. ${ }^{10} \mathrm{The} \mathrm{C}_{9}-\mathrm{C}_{4}$ ' bond was found to possess unusual restriction leading to slow exchange between the synand the anti-conformers, which clearly indicates a considerable steric encumbrance around the $\mathrm{C}_{9}$ atom. Interestingly, ether $\mathbf{2 a}$, prepared through the methylation of the hydroxyl group in 1, demonstrates an exceptionally broad signal in ${ }^{19} \mathrm{~F}$ NMR spectrum at $298 \mathrm{~K}$ (Entry 1, Table 1). Upon lowering the temperature, the signal broadens further and then appears as three individual sharp pseudo triplets, indicating a gradual decrease in rotational rates. At $223 \mathrm{~K}$, a clear first order AEM-type spin system exhibits ${ }^{2} J_{\mathrm{F}-\mathrm{F}}$ coupling constants of ca. 115 $\mathrm{Hz}$ and reveals the freezing of the rotation about the $\mathrm{CF}_{3}-\mathrm{C}_{9}$ bond on the NMR time scale. Furthermore, hindered $\mathrm{CF}_{3}$ rotations were also observed when a number of alkyl groups $(\mathrm{R})$ possessing various steric demands were incorporated into $\mathbf{1}$ (2b-2e), (Entries 2-5, Table 1). The ${ }^{19}$ F NMR spectra of $\mathbf{2 c}-2 \mathbf{e}$ display partially decoalesced resonances even at $298 \mathrm{~K}$, showing high barrier restricted rotations about the $\mathrm{CF}_{3}-\mathrm{C}_{9}$ bonds.

It has been shown that cinchona alkaloid derivatives can adopt various conformations under different conditions. ${ }^{11}$ To identify the conformations responsible for the restricted $\mathrm{CF}_{3}$ rotations, exhaustive experimental and computational studies were performed. Based on

*Fax: (+1) 213-740-6679 gprakash@usc.edu, olah@usc.edu.

Supporting information for this article is available on the WWW under http://www.angewandte.org or from the author. 
nuclear Overhauser enhancement spectroscopic studies (NOESY), 2a was found to preferentially adopt a syn-closed conformation (Figure 1-A), (See SI). In addition, throughspace couplings were observed between the $\mathrm{CF}_{3}$ group and the $\mathrm{OCH}_{3}$ group $\left({ }^{5} \mathrm{~J}_{\mathrm{F}-\mathrm{C}\left(\mathrm{H}_{3}\right)}=1.9\right.$ $\left.\mathrm{Hz} ;{ }^{4} \mathrm{~J}_{\mathrm{F}-(C) \mathrm{H} 3}=1.6 \mathrm{~Hz}\right)$, indicating an interaction between these two functionalities. ${ }^{12} \mathrm{~A}$ close contact between the $\mathrm{CF}_{3}$ group and the $\mathrm{C}_{3^{\prime}}-\mathrm{H}_{1}$ substructure was also evident by the corresponding scalar couplings $\left({ }^{5} J_{\mathrm{F}-\mathrm{H} 1}=1.6 \mathrm{~Hz} ;{ }^{J} J_{\mathrm{F}-\mathrm{C} 3^{\prime}}=3.9 \mathrm{~Hz}\right)$, further validating the syn-closed structure.

Our DFT calculations indicate the syn-closed conformation of 2a to be $1.9 \mathrm{kcal} / \mathrm{mol}$ lower in energy than the anti-closed conformation in chloroform, ${ }^{13}$ corresponding to a population distribution of 94:6 (syn-closed:anti-closed), consistent with the population ratio observed in the ${ }^{19} \mathrm{~F}$ NMR spectrum (ca. 95:5). ${ }^{14}$ The accuracy of the B3LYP method is expected to be ca. $\pm 2 \mathrm{kcal} / \mathrm{mol}$ in this case. Therefore, the observed good agreement with the experiment is in part fortuitous. Several short H/C-F contacts in the syn-closed conformation are responsible for the observed through-space H-F and C-F couplings (Figure 1-B). The computed individual chemical shifts of the fluorine nuclei in $\mathbf{3}$ are in good agreement with the NMR spectroscopic study (Figure 1-C). We also performed a potential energy surface (PES) scan for the $\mathrm{CF}_{3}$ rotations in the syn-closed-2a and the anti-closed-2a conformers with implicit consideration of solvent $\mathrm{CHCl}_{3}$-solvation. The $\mathrm{CF}_{3}$ rotational barriers in the syn-closed and the anti-closed conformations were calculated to be $12.1 \mathrm{kcal} / \mathrm{mol}$ and 6.8 $\mathrm{kcal} / \mathrm{mol}$, respectively. These two conformations likely correspond to the broad and the sharp peaks observed in the ${ }^{19} \mathrm{~F}$ NMR spectrum (See SI).

The preference for the syn-closed conformation was also confirmed by the X-ray crystal structure of $\mathbf{2 c}$ (Figure 2-A). The interatomic distances between $\mathrm{F}$ atoms and majority of the surrounding protons were within the sum of van der Waals radii (ca. $2.5 \AA$ ) (Figure 2-B). ${ }^{9 \mathrm{~d}}$ In particular, a short C-H $\cdots$ F-C distance of $2.26 \AA$ was found between $\mathrm{F}_{1}$ and $\mathrm{H}_{1}$ (corresponding to the computed distance of $2.19 \AA$ in $\mathbf{2 a}$ ), which is among the shortest C$\mathrm{H} \cdots \mathrm{F}-\mathrm{C}$ contacts ever reported in the solid state. ${ }^{9 \mathrm{f}, 9 \mathrm{i}}$

To make a quantitative assessment of the rotational barriers in 2a-2e, dynamic NMR (DNMR) experiments were performed (See SI). Utilizing Eyring plots, activation enthalpies and entropies of the rotations of $\mathbf{2 a - 2 e}$ were determined to show first order relationships. The enthalpy barriers $\left(\Delta \mathrm{H}^{\ddagger}\right)$ of the $\mathrm{CF}_{3}$ rotations were found to increase as the substituent was altered from a methyl group to an allyl group (ca. $9.0 \mathrm{kcal} / \mathrm{mol}$ versus ca. $10.1 \mathrm{kcal} /$ mol). However, no significant impact on the activation enthalpies was found by further increasing the bulkiness of the substituents $(R)(\mathbf{2 a}<\mathbf{2} \mathbf{b} \approx \mathbf{2} \mathbf{c} \approx \mathbf{2} \mathbf{d} \approx \mathbf{2} \mathbf{e}$, Table 1). Compared with other substituents possessing lower symmetries, the $\mathrm{CH}_{3}$ group in $\mathbf{2 a}$ can undergo a correlated rotation with the $\mathrm{CF}_{3}$ rotation, thereby releasing more steric strain $\left(\Delta \mathrm{H}^{\ddagger}\right)$ in the transition state (TS) than other substituents. On the other hand, as shown by conformational studies, $\mathrm{CF}_{3} \cdots \mathrm{R}-\mathrm{O}$ interactions in $\mathbf{2 b}-\mathbf{2 e}$ only occur between the $\mathrm{CF}_{3}$ group and the intervening methylene group in $\mathrm{R}$. Therefore, the increase in the bulkiness of $\mathrm{R}$ does not significantly increase the steric strain around the $\mathrm{CF}_{3}$ groups in $\mathbf{2 b}-\mathbf{2} \mathbf{e}$, neither in the TS nor in the ground state. Noticeably, $\Delta S^{\ddagger}$ was found to increase in $\mathbf{2 b}$ to $\mathbf{2 e}$, following their increase in size. 2a stands out with a small $\mathrm{R}$ group but a large $\Delta \mathrm{S}^{\ddagger}$ value, the latter comparable to those of $\mathbf{2} \mathbf{b}-\mathbf{2 d}$. This might be attributed to the ground state of $\mathbf{2 a}$, in which the $\mathrm{CH}_{3}$ group has a largely unhindered rotation, contrary to the bulkier $\mathrm{R}$ groups of $\mathbf{2 b}-\mathbf{2 d}$. The entropic effect of hindering the $\mathrm{CH}_{3}$ rotation in the TS will thus be relatively large in 2a. Such hindered $\mathrm{CH}_{3}$ rotation is also indicated in our DFT calculations, which show a contraction of the $\mathrm{C}^{-} \mathrm{F}_{3} \cdots \mathrm{H}_{3} \mathrm{CO}$ distance by $0.31 \AA$ (12\%) in $\mathbf{2 a}$.

Having a wealth of valuable geometric and spectroscopic information in hand, we were able to explore the nature of the $\mathrm{C}-\mathrm{F}_{1} \cdots \mathrm{H}_{1}-\mathrm{C}_{3}$ interactions and their effects on the hindered $\mathrm{CF}_{3}$ 
rotations. First of all, in addition to the short $\mathrm{C}-\mathrm{F}_{1} \cdots \mathrm{H}_{1}-\mathrm{C}_{3^{\prime}}$ distance in $2 \mathrm{c}$, the $\mathrm{C}_{3^{\prime}}-\mathrm{H}_{1} \cdots \mathrm{F}$ angle is $130.1^{\circ}$, which fulfills the directionality requirement for hydrogen bonding $\left(>110^{\circ}\right) .{ }^{15,16}$ Noticeable proton deshieldings for $\mathrm{H}_{1}(\delta>7.42 \mathrm{ppm}$ versus $\delta=7.33$ in $\mathbf{1})$ were also observed in $\mathbf{2}$, which could be indicative for the occurrence of C-F ${ }^{\cdots} \mathrm{H}_{1}-\mathrm{C}_{3^{\prime}}$ hydrogen bonding (Figure 3). ${ }^{15,17}$ It is worth noting that ${ }^{5} \mathrm{~J}_{\mathrm{F}-\mathrm{H} 1}$ constants in $\mathbf{2 a - 2 e}$ are essentially identical $(1.6 \sim 1.7 \mathrm{~Hz})$, which indicates very similar C-F $\cdots \mathrm{H}_{1}-\mathrm{C}_{13}$. distances. ${ }^{12 \mathrm{a}}$ Thus, lower field chemical shifts observed in $\mathbf{2 c}-\mathbf{2 e}$, compared with those of $\mathbf{2 a}$ and $\mathbf{2 b}$, are probably due to increased ring current induced deshieldings from different aromatic substructures, instead of stronger hydrogen bonding interactions or shorter $\mathrm{H}^{\cdots} \mathrm{F}$ distances.

In addition, several delocalized molecular orbitals can be envisioned between the $\mathrm{CF}_{3}$ group and the surrounding hydrogen atoms (Table 2). ${ }^{13}$ This is particularly obvious for the C$\mathrm{F}^{\cdots} \mathrm{H}_{1}-\mathrm{C}_{3}$ interaction. To estimate the magnitude of the different interactions, Wiberg bond indices ${ }^{18}$ were calculated from natural atomic orbitals (NAO). ${ }^{13}$ The bond index for the strongest interaction $\left(\mathrm{C}-\mathrm{F}_{1} \cdots \mathrm{H}_{1}-\mathrm{C}_{3^{\prime}}\right)$ was found to be 0.0055 . This suggests a relatively weak hydrogen bonding-like interaction as compared with the $\mathrm{H}^{\cdots} \mathrm{F}$ hydrogen bonding in the $\mathrm{HF}$ dimer (with bond index of 0.0296 and bonding energy of $4.6 \mathrm{kcal} / \mathrm{mol}$ ) ${ }^{19}$ and the $\mathrm{C}-\mathrm{H} \cdots \mathrm{F}-\mathrm{C}$ hydrogen bondings in the $\mathrm{CH}_{2} \mathrm{~F}_{2}$ dimer (with bond indices of $0.0007-0.0018$ and an average hydrogen bonding energy of $0.6 \mathrm{kcal} / \mathrm{mol}) .{ }^{9 \mathrm{~h}}$ The remaining six $\mathrm{C}-\mathrm{F} \cdots \mathrm{H}-\mathrm{C}$ interactions were calculated to only $13-31 \%$ of this value. Additionally, NBO second-order perturbation analysis ${ }^{20}$ was used to estimate the interaction energies of the fluorine lone pairs with the $\mathrm{C}_{3^{\prime}}-\mathrm{H}_{1}$ anti-bonding orbital. It is well established that such hyperconjugative interactions, which are a measure of charge transfer, are the major contributors to hydrogen bonding. ${ }^{20 \mathrm{a}}$ The two relevant $\mathrm{n}_{\mathrm{F}} \rightarrow \sigma^{*}{ }_{\mathrm{H} 1-\mathrm{C} 3}$ interaction energies were found to be only 0.6 and $1.3 \mathrm{kcal} /$ mol, further suggesting a rather limited contribution of the $\mathrm{C}-\mathrm{F}_{1} \cdots \mathrm{H}_{1}-\mathrm{C}_{3^{\prime}}$ hydrogen bonding interaction to the overall rotational barrier.

Investigation of the TS structure has revealed the importance of the steric strain to the hindered rotation. The $\mathrm{CF}_{3}$ group was found to undergo noticeable geometric distortions in the TS, indicating an increased steric strain upon rotation. ${ }^{21}$ Also worth noting is the $0.05 \AA$ (ca. $2 \%$ ) contraction of the $\mathrm{F}_{1} \cdots \mathrm{H}_{1}$ distance in the TS corresponding to $\mathrm{CF}_{3}$ rotation. Despite a shorter distance, which is typically taken as an indication of a stronger $\mathrm{H}$-bonding interaction, the single $n_{F} \rightarrow \sigma^{*}{ }_{H} 1-C^{\prime}$ interaction energy is reduced to $0.5 \mathrm{kcal} / \mathrm{mol}$. This again hints to a limited importance of the $\mathrm{C}-\mathrm{F}_{1} \cdots \mathrm{H}_{1}-\mathrm{C}_{3}$, H-bonding interaction to the actual ground state geometry or the hindered rotation in this studied system. In other words, the extraordinary short $\mathrm{F}_{1} \cdots \mathrm{H}_{1}$ distance in $\mathbf{2 a}$ appears to be a consequence of steric crowding (buttressing), rather than any meaningful measurable of hydrogen bonding interaction. The weakness of these $\mathrm{C}-\mathrm{F}_{1} \cdots \mathrm{H}_{1}-\mathrm{C}_{3}$ interactions is in sharp contrast to $\mathrm{C}-\mathrm{F} \cdots \mathrm{H}-\mathrm{N}^{+} \mathrm{R}_{3} \mathrm{H}-$ bonding, which are strengthened by stronger acidities of $\mathrm{H}-\mathrm{N}^{+} \mathrm{R}_{3}$ type motives. ${ }^{9}$

In conclusion, we have investigated hindered $\mathrm{CF}_{3}$ rotations in cinchona alkaloid-based scaffolds. DNMR studies have shown the barriers to rotations in the range of 11.9 to 13.5 $\mathrm{kcal} / \mathrm{mol}$. The increase in the hindrance of the $\mathrm{CF}_{3}$ rotations in $\mathbf{2} \mathbf{b}-\mathbf{2 e}$ is driven by the difference in their entropic changes. Quantum mechanical and experimental studies have shown that the non-covalent $\mathrm{C}_{3}{ }^{\prime}-\mathrm{H}_{1} \cdots \mathrm{F}-\mathrm{C}$ interactions possess some hydrogen bonding-like character. Nonetheless, their contributions to the restricted $\mathrm{CF}_{3}$ rotations are rather limited. Instead, the steric interactions between the $\mathrm{C}_{3}-\mathrm{H}_{1}$ moiety and the $\mathrm{CF}_{3}$ group plays a pivotal role in the hindered rotations in the present systems.

\section{Supplementary Material}

Refer to Web version on PubMed Central for supplementary material. 


\section{Acknowledgments}

Support of our work by the Loker Hydrocarbon Research Institute is gratefully acknowledged. Dr. S. Khan in the Department of Chemistry and Biochemistry at the University of California, Los Angeles is gratefully thanked for the assistance on the crystal structure. We appreciate grants from the NSF (DBI-0821671, CHE-0840366) and NIH (S10 RR25432) to support NMR spectrometers. The computational studies were supported by the University of Southern California Center for High-Performance Computing and Communications.

\section{References}

[1]. Orville-Thomas, WJ. Internal Rotations in Molecules. Orville-Thomas, WJ., editor. Wiley; London, New York: 1974.

[2]. (a) Ōki M. Acc. Chem. Res. 1990; 23:351.(b) Mati IK, Cockroft SL. Chem. Soc. Rev. 2010; 39:4195. [PubMed: 20844782]

[3]. (a) Chen Y, Yekta S, Yudin AK. Chem. Rev. 2003; 103:3155. [PubMed: 12914495] (b) Brunel JM. Chem. Rev. 2007; 107:PR1.(b) Clayden J, Moran WJ, Edwards PJ, LaPlante SR. Angew. Chem. 2009; 121:6516. Angew. Chem. Int. Ed. 2009, 48, 6398. (c) Bringmann G, Gulder T, Gulder TAM, Breuning M. Chem. Rev. 2011; 111:563. [PubMed: 20939606]

[4]. (a) Kelly TR. Acc. Chem. Res. 2001; 34:514. [PubMed: 11412088] (b) Kottas GS, Clarke LI, Horinek D, Michl J. Chem. Rev. 2005; 105:1281. [PubMed: 15826014] (c) Kay ER, Leigh DA, Zerbetto F. Angew. Chem. 2007; 119:72. Angew. Chem. Int. Ed. 2007, 46, 72. [PubMed: 17133632]

[5]. Ōki, M. Applications of Dynamic NMR Spectroscopy to Organic Chemistry. Vol. chap. 6. VCH Publishers; Deerfield Beach, Florida: 1985.

[6]. The barriers to rotations about $\mathrm{F}_{3} \mathrm{C}-\mathrm{C}\left(s p^{3}\right)$ bonds are usually rather low. Lowe JP. Streitwieser A Jr, Taft RW. Progress in Physical Organic Chemistry. 1968:36.John Wiley and Sons.

[7]. Kareev et al. have summarized hindered rotations of $\mathrm{CF}_{3}-\mathrm{C}\left(s p^{3}\right)$ bonds, Kareev IE, SantisoQuinones G, Kuvychko IV, Ioffe IN, Goldt IV, Lebedkin SF, Seppelt K, Strauss SH, Boltalina OV. J. Am. Chem. Soc. 2005; 127:11497. [PubMed: 16089480] .

[8]. Only a single report has demonstrated that the rotational barrier of $\mathrm{CF}_{3}-\mathrm{C}\left(s p^{3}\right)$ bonds can be higher than $25 \mathrm{kcal} / \mathrm{mol}$, Toyota S, Watanabe Y, Yoshida H, Ōki M. Bull. Chem. Soc. Jpn. 1995; 68:2751..

[9]. Selected examples and review articles on C-F $\cdots$ H-X: West R, Powell DL, Whatley LS, Lee MKT, Schleyer PR. J. Am. Chem. Soc. 1962; 84:3221.; Shimoni L, Glusker JP, Bock CW. J. Phys. Chem. 1995; 99:1194.; Howard JAK, Hoy VJ, O'Hagan D, Smith GT. Tetrahedron. 1996; 52:12613.; Dunitz JD, Taylor R. Chem. Eur. J. 1997; 3:89.; Wang X, Houk KN. Chem. Commun. 1998:2631.; Thalladi VR, Weiss H-C, Bläser D, Boese R, Nangia A, Desiraju GR. J. Am. Chem. Soc. 1998; 120:8702.; Barbarich TJ, Rithner CD, Miller SM, Anderson OP, Strauss SH. J. Am. Chem. Soc. 1999; 121:4280.; Caminati W, Melandri S, Moreschini P, Favero PG. Angew. Chem. 1999; 111:3105. Angew. Chem. Int. Ed. 1999, 38, 2924. ; Parsch J, Engels JW. J. Am. Chem. Soc. 2002; 124:5664. [PubMed: 12010039] ; Kui SCF, Zhu N, Chan MCW. Angew. Chem. 2003; 115:1666. Angew. Chem. Int. Ed. 2003, 42, 1628. ; Hof F, Diederich F. Chem. Commun. 2004:484.; Samsonov SA, Salwiczek M, Anders G, Koksch B, Pisabarro MT. J. Phys. Chem. B. 2009; 113:16400. [PubMed: 19947631] ; Anzahaee MY, Watts JK, Alla NR, Nicholson AW, Damha MJ. J. Am. Chem. Soc. 2011; 133:728. [PubMed: 21171597] ; Scerba MT, Leavitt CM, Diener ME, DeBlase AF, Guasco TL, Siegler MA, Bair N, Johnson MA, Lectka T. J. Org. Chem. 2011:76. 10.1021/jo2015328. .

[10]. Prakash GKS, Wang F, Ni C, Shen J, Haiges R, Yudin AK, Mathew T, Olah GA. J. Am. Chem. Soc. 2011; 133:9992. [PubMed: 21648459]

[11]. (a) Dijkstra GDH, Kellogg RM, Wynberg H, Svendsen JS, Marko I, Sharpless KB. J. Am. Chem. Soc. 1989; 111:8069.(b) Aune M, Gogoll A, Matsson O. J. Org. Chem. 1995; 60:1356.(c) Bürgi T, Baiker A. J. Am. Chem. Soc. 1998; 120:12920.(d) Urakawa A, Meier DM, Rüegger H, Baiker A. J. Phys. Chem. A. 2008; 112:7250. [PubMed: 18636698]

[12]. (a) Myhre PC, Edmonds JW, Kruger JD. J. Am. Chem. Soc. 1966; 88:2459.(b) Wasylishen RE, Barfield M. J. Am. Chem. Soc. 1974; 97:4545.(c) Dolbier, WR. Guide to Fluorine NMR for Organic Chemists. Vol. Chap. 1. John Wiley \& Sons; Hoboken, New Jersey: 2009. 
[13]. (a) Computed using the Gaussian 03, Revision C.02, M. J. Frisch, Gaussian, Inc., Wallingford CT, 2004; (b) Details of the compuational studies are included in the Supporting Information.

[14]. In addition to the broad/decoalesced signal observed in each case, a sharp peak (with a relative population of ca. $5 \%$ according to the ${ }^{19}$ FNMR integrations) was also observed that shows temperature dependence in its lineshape.

[15]. Steiner T, Desiraju GR. Chem. Commun. 1998:891.

[16]. Desiraju GR. Angew. Chem. 2011; 123:52. Angew. Chem. Int. Ed. 2011, 50, 52. [PubMed: 21031379]

[17]. Pimentel, GC.; McClellan, AL. The Hydrogen Bond. Reinhold Publishing Corporation; New York: 1960. p. 142

[18]. Wiberg KB. Tetrahedron. 1968; 24:1083.

[19]. Bohac EJ, Marshall MD, Miller RE. J. Chem. Phys. 1992; 96:6681.

[20]. Reed AE, Curtiss LA, Weinhold F. Chem. Rev. 1988; 88:899.Recent examples utilizing second order perturbation analysis to estimate intramolecular H-bond strengths, Tian SX, Li H-B. J. Phys. Chem. A. 2007; 111:4404. [PubMed: 17461561] ; Shchavlev AE, Pankratov AN, Enchev V. J. Phys. Chem. A. 2007; 111:7112. [PubMed: 17616175] ; Jesus AJL, Rosado MTS, Reva I, Fausto R, Eusébio MES, Redinha JS. J. Phys. Chem. A. 2008; 112:4669. [PubMed: 18444635] ; Lämmermann A, Szátmari I, Fülöp F, Kleinpeter E. J. Phys. Chem. A. 2009; 113:6197. [PubMed: 19422183] .

[21]. Several obvious distortions in the transition state include the increase in the $\mathrm{F}_{3} \mathrm{C}-\mathrm{C}_{9}$ bond distance (from $1.580 \AA$ to $1.621 \AA$ ) and the increase in the $\mathrm{F}_{1}-\mathrm{C}-\mathrm{C}_{9}$ angle (from $113.3^{\circ}$ to $116.0^{\circ}$ ). 
A
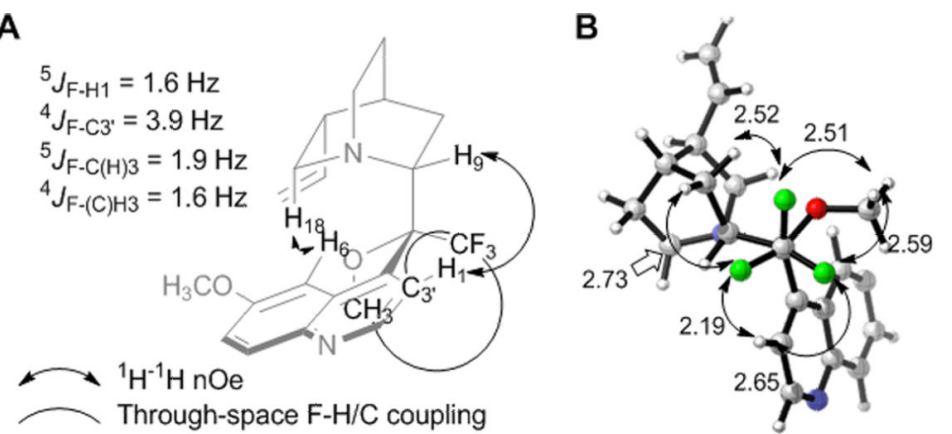

c

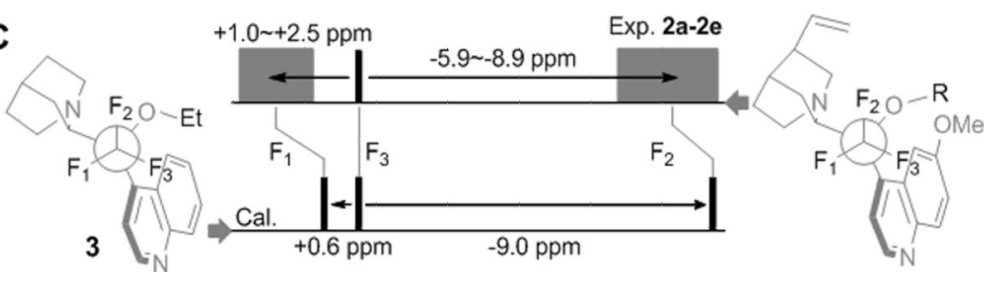

Figure 1.

A. Conformational analysis of 2a based on NMR spectroscopic studies; B. Optimized conformation of 2a at the B3LYP/6-31+G(d,p) level in the gas phase (the OMe group on the quinoline ring is omitted for clarity.); C. Calculated ${ }^{19} \mathrm{~F}$ NMR chemical shifts of $\mathbf{3}$ and experimental ${ }^{19} \mathrm{~F}$ NMR chemical shifts of $\mathbf{2}$. 
A

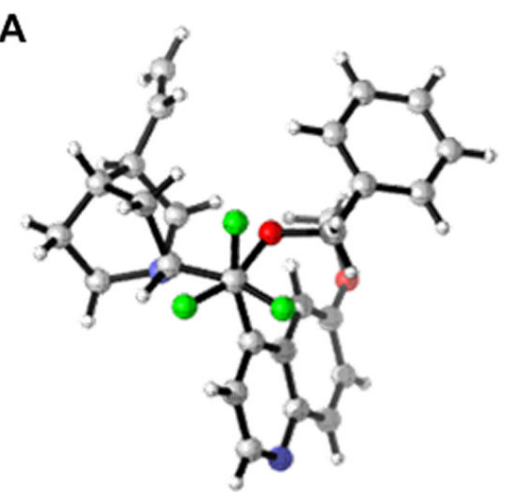

B

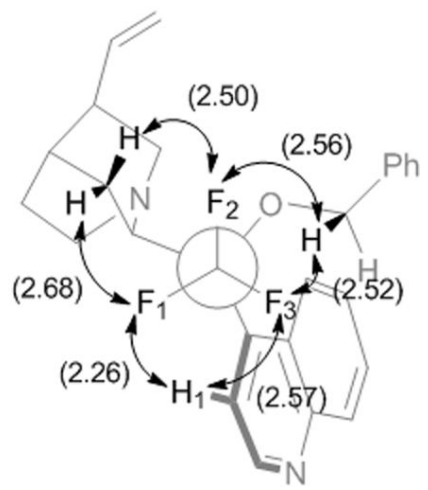

Figure 2.

A. X-ray crystal structure of $\mathbf{2 c}$; B. Short proton-fluorine contacts as indicated by the crystal structure of $\mathbf{2 c}$ (as the average values measured in both molecules in the unit cell). 


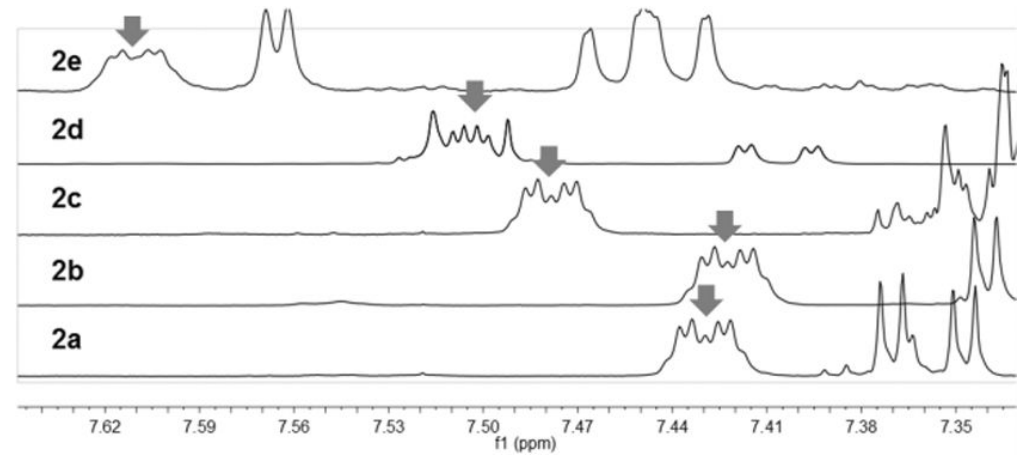

Figure 3.

${ }^{1} \mathrm{H}$ NMR chemical shifts of $\mathrm{H}_{1}$ in $\mathbf{2 a} \mathbf{a}-\mathbf{2 e}$ in $\mathrm{CDCl} 3$. The chemical shift of $\mathrm{H}_{1}$ in $\mathbf{2 d}$ was estimated through HSQC spectroscopy. 

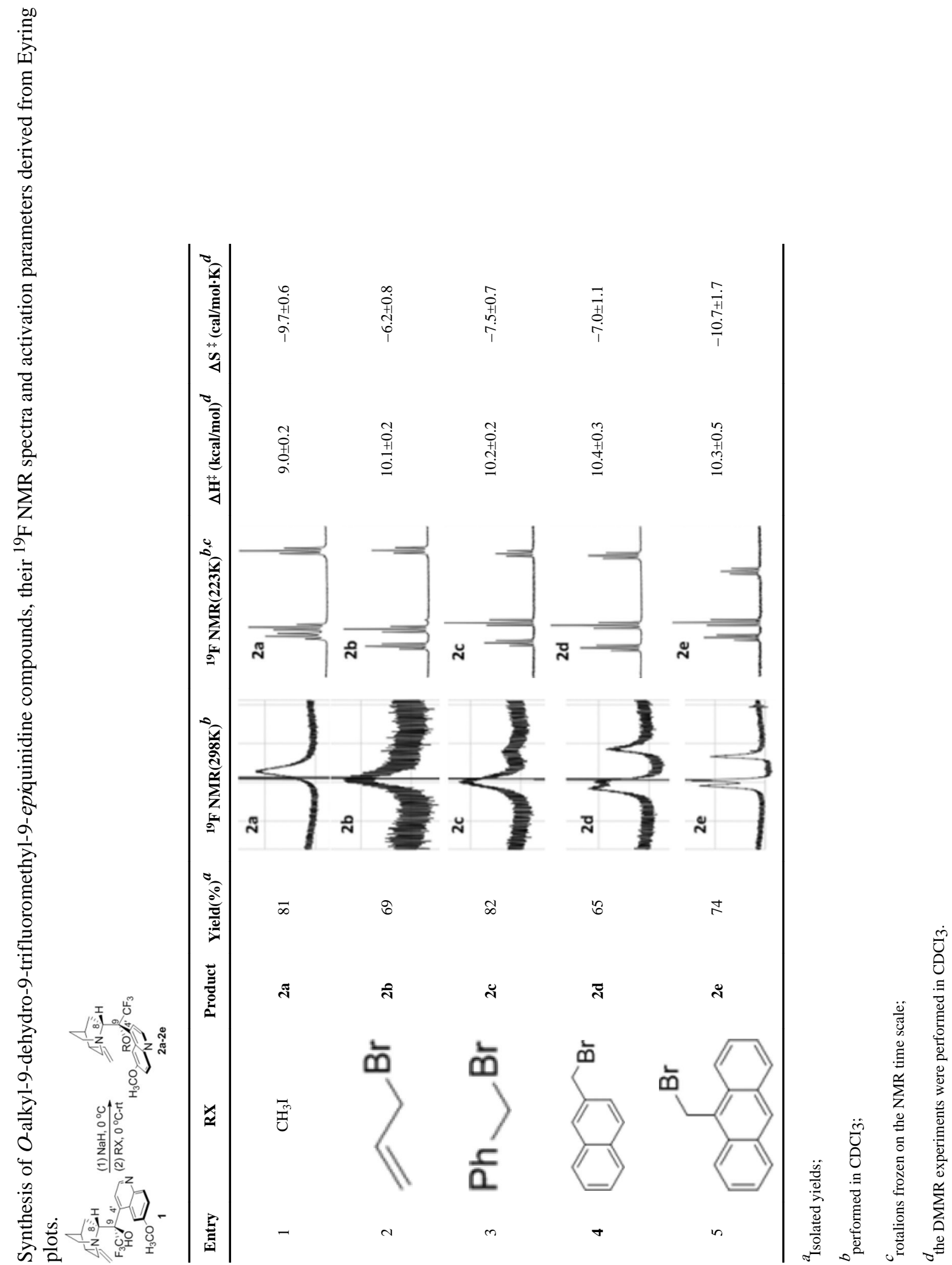
Table 2

Canonical MOs showing $\mathrm{C}_{3},-\mathrm{H}_{1} \cdots \mathrm{F}_{1}-\mathrm{C}$ interactions in 3.

\begin{tabular}{|c|c|c|c|}
\hline MO Number & $\begin{array}{c}\text { Cartoon representations of contributing } \\
\text { atomic orbitals }\end{array}$ & Cartoon representations of $\mathrm{H}-\mathrm{F}$ interactions & Computed MO's \\
\hline MO-69 & & & \\
\hline MO-63 & & & \\
\hline MO-59 & & & \\
\hline MO-44 & & & \\
\hline
\end{tabular}

